\title{
Mental health-related visits in a pediatric emergency department during the COVID- 19 pandemic
}

\author{
Arnaud Fernandez ${ }^{1,2^{*}}$ D Morgane Gindt ${ }^{1,2}$, Phillipe Babe ${ }^{3}$ and Florence Askenazy ${ }^{1,2}$
}

\begin{abstract}
We aimed to describe the epidemiology of all pediatric emergency department visits (focusing on mental healthrelated visits versus total visits) at the University Children's Hospital of Nice (France) from 1 January to 31 December 2020 (year of the COVID-19 pandemic) and to compare it with the earlier 3-year period. The increase in mental health-related visits (44.2\%) that we observed, while total visits decreased (30.0\%), suggests an impact of the pandemic on children's and adolescents' mental health.
\end{abstract}

Keywords: COVID-19 pandemic, Child and adolescent psychiatry, Mental health, Pediatric emergency department visits

\section{Introduction}

The year 2020 was marked by the worldwide spread of an emerging virus: severe acute respiratory syndrome coronavirus 2 (SARS-CoV-2).

Comparatively to older adults, children and adolescents are currently less affected by severe and fatal forms of the coronavirus disease 2019 (COVID-19) caused by SARS-CoV-2 infection [1], but are confronted with surrounding anxiety and the worry of being infected [2].

At the University Pediatric Hospital of Nice (UPHN), total visits (including mental health-related visits) to the Pediatric Emergency Department (PED) have been increasing for almost 10 years [3] with relative stability over the last 3 years. Nevertheless, according to literature data, we could hypothesize that we will observe a decrease of all PED visits during the pandemic [4].

The aim of this study was to describe the epidemiology of all PED visits (focusing on mental health-related visits

\footnotetext{
* Correspondence: fernandez.a@pediatrie-chulenval-nice.fr

${ }^{1}$ Child and Adolescent Psychiatry Department, Children's Hospitals of Nice

CHU-Lenval, 57, Avenue de la Californie, 06200 Nice, France

2Université Côte d'Azur, CoBTek, Nice, France

Full list of author information is available at the end of the article
}

versus total visits) at the UPHN from 1 January to 31 December 2020 and to compare it with the earlier 3year period.

\section{Methods}

We collected PED visit rates and characteristics at the UPHN. These data were collected over a period ranging from 3 years before the pandemic to the current year of the pandemic (1 January 2017-31 December 2020). We carried out an analysis of the ICM-10 diagnoses and extracted all mental health-related visits (e.g., suicide attempts, suicidal ideation or anxiety). All visits of patients aged 0 to 18 years were included. Then we compared the number of visits to PED in the pandemic period (ranging from 1 January to 31 December 2020) to the number of visits to PED in the 3-year period (mean value) before the pandemic. We analyzed both total and mental health-related visits.

\section{Results}

The rate of total PED visits in 2020 decreased by $30.0 \%$ (42 985 visits) in comparison to the average rate from 2017 to 2019 (61,434 visits in average and 


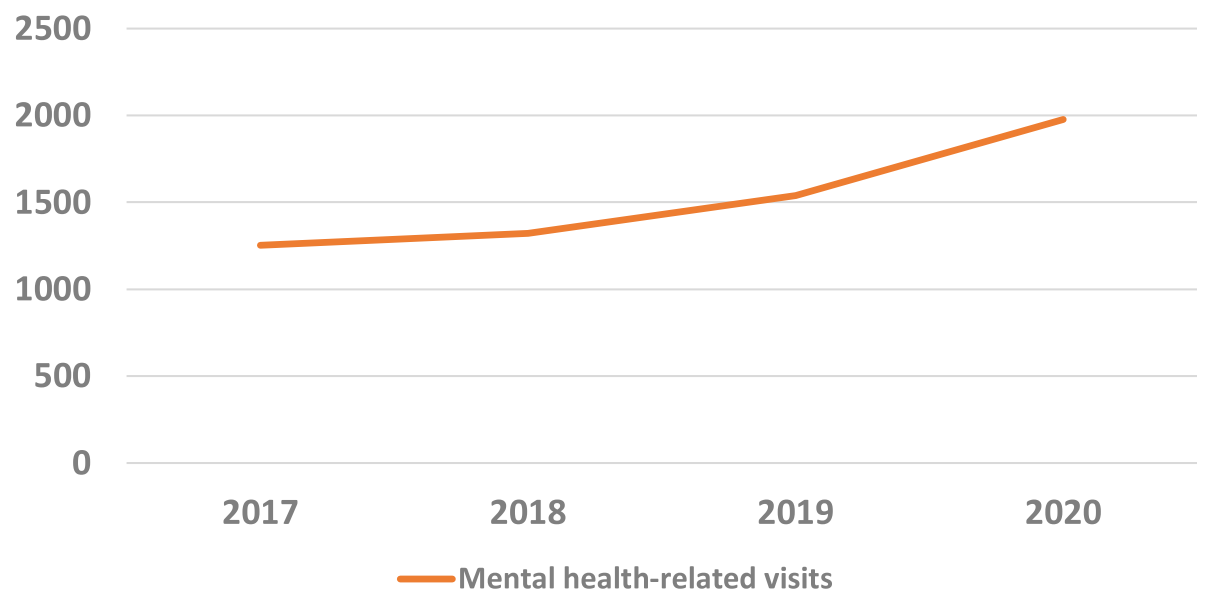

Fig. 1 Epidemiology of pediatric emergency department mental health-related visits

$62,429,60,429$ and 61,445 respectively from 2017 to 2019). The rate of mental health-related visits increased by $44.2 \%$ (1977 visits) in comparison to the average rate from 2017 to 2019 (1371 visits in average). Data are presented in Fig. 1.

\section{Discussion}

The COVID-19 pandemic is marked by a major decrease of total visits (27 PEDs in the USA from 15 March to 31 August 2020 vs a 3-year earlier comparator period with a total rate of visits down by 45.7\%) [4] and an increase of the proportion of mental health-related visits (data from CDC's National Syndromic Surveillance Program in the USA from 1 January to 7 October 2020 vs the same period in 2019) [5].

Although it is difficult to statistically compare our population with the one mentioned above, the difference observed in this large North American pediatric population seems to be consistent with our results. Indeed, the PED of the UPHN is the fourth site in France in terms of number of visits and the only one for the East PACA region which has more than one million inhabitants. The increase in mental health-related visits (44.2\%) that we observed, while total visits decreased (30.0\%), suggests an impact of the pandemic on children's and adolescents' mental health. Indeed, negative mental health effects have already been linked to home confinement among Chinese children [2] and an increased rate of suicide ideation has been observed during the pandemic among North American adolescents [6]. Recently, a stable pattern of behavioral inhibition in childhood has been shown to predict heightened anxiety in adults facing the pandemic [7].

Thus, further longitudinal studies with a developmental approach in various countries are needed to understand the underlying mechanisms of the pandemic impact on youth mental health.

\section{Acknowledgements}

We are grateful to Philippe Robert, Anamaria Bogdan, Maria Capovilla, and Philippe Auby for their comments on the manuscript. We thank Roxane Fabre for statistical help.

\section{Authors' contributions}

$A F$ and FA: contributed to the conceptualization of the study and drafted the first version of the manuscript. All authors AF, FA, MG, and PB have revised first version of the manuscript critically for important intellectual content and approved the final version. All authors read and approved the final manuscript.

Funding

None

Availability of data and materials

The data that support the findings of this study are available on request from the corresponding author.

\section{Declarations}

Ethics approval and consent to participate

CERNI (Ethics committee for non-interventional research), Université Côte d'Azur (UCA), France ( $\left.n^{\circ} 2021-042\right)$

Consent for publication

Not applicable

\section{Competing interests}

The authors declare that they have no competing interests.

\section{Author details}

${ }^{1}$ Child and Adolescent Psychiatry Department, Children's Hospitals of Nice CHU-Lenval, 57, Avenue de la Californie, 06200 Nice, France. ${ }^{2}$ Université Côte d'Azur, CoBTek, Nice, France. ${ }^{3}$ Pediatric Emergency Department, Children's Hospitals of Nice CHU-Lenval, 57, Avenue de la Californie, 06200 Nice, France.

Received: 11 May 2021 Accepted: 7 October 2021

Published online: 04 November 2021

References

1. Zachariah P, Johnson CL, Halabi KC, Ahn D, Sen Al, Fischer A, et al. Epidemiology, clinical features, and disease severity in patients with coronavirus disease 2019 (COVID-19) in a children's hospital in New York City, New York. JAMA pediatrics. 2020;174(10):e202430. https://doi.org/10.1 001/jamapediatrics.2020.2430.

2. Xie X, Xue Q, Zhou Y, Zhu K, Liu Q, Zhang J, et al. Mental health status among children in home confinement during the coronavirus disease 2019 
outbreak in Hubei Province, China. JAMA pediatrics. 2020;174(9):898-900. https://doi.org/10.1001/jamapediatrics.2020.1619.

3. Lotte J-B, Askenazy F, Babe P, Fernandez A. Why an on-site inpatient pediatric psychiatric unit is needed to improve mental health care in the Pediatric Emergency Department of Lenval Hospital, Nice, France. Pediatric emergency care. 2017;33(8):e32. https://doi.org/10.1097/PEC. 0000000000001224

4. DeLaroche AM, Rodean J, Aronson PL, et al. Pediatric emergency department visits at US children's hospitals during the COVID-19 pandemic. Pediatrics. 2021;147(4):e2020039628. https://doi.org/10.1542/peds.2020-03 9628.

5. Leeb RT, Bitsko RH, Radhakrishnan L, Martinez P, Njai R, Holland KM. Mental health-related emergency department visits among children aged $<18$ years during the COVID-19 pandemic - United States, January 1-October 17, 2020. MMWR Morb Mortal Wkly Rep. 2020;69(45):1675-80. https://doi.org/1 0.15585/mmwr.mm6945a3.

6. Hill RM, Rufino K, Kurian S, Saxena J, Saxena K, Williams L. Suicide ideation and attempts in a pediatric emergency department before and during CoViD-19. Pediatrics. 2021;147(3):e2020029280. https://doi.org/10.1542/ peds.2020-029280.

7. Zeytinoglu S, Morales S, Lorenzo NE, Chronis-Tuscano A, Degnan KA, Almas AN, et al. A developmental pathway from early behavioral inhibition to young adults' anxiety during the COVID-19 pandemic. Journal of the American Academy of Child \& Adolescent Psychiatry. 2021;60(10):1300-8. https://doi.org/10.1016/j.jaac.2021.01.021.

\section{Publisher's Note}

Springer Nature remains neutral with regard to jurisdictional claims in published maps and institutional affiliations.

Ready to submit your research? Choose BMC and benefit from:

- fast, convenient online submission

- thorough peer review by experienced researchers in your field

- rapid publication on acceptance

- support for research data, including large and complex data types

- gold Open Access which fosters wider collaboration and increased citations

- maximum visibility for your research: over $100 \mathrm{M}$ website views per year

At BMC, research is always in progress.

Learn more biomedcentral.com/submissions 